\title{
GCU
}

Glasgow Caledonian

University

University for the Common Good

\section{Fatigue alters the pattern of physical activity behavior in older adults: observational analysis of data from the Generation $\mathbf{1 0 0}$ study}

Egerton, Thorlene; Helbostad, Jorunn L.; Stensvold, Dorthe; Chastin, Sebastien F. M.

Published in:

Journal of Aging and Physical Activity

DOI:

10.1123/japa.2015-0237

Publication date:

2016

Document Version

Author accepted manuscript

Link to publication in ResearchOnline

Citation for published version (Harvard):

Egerton, T, Helbostad, JL, Stensvold, D \& Chastin, SFM 2016, 'Fatigue alters the pattern of physical activity behavior in older adults: observational analysis of data from the Generation 100 study', Journal of Aging and Physical Activity, vol. 24, no. 4, pp. 633-641. https://doi.org/10.1123/japa.2015-0237

\section{General rights}

Copyright and moral rights for the publications made accessible in the public portal are retained by the authors and/or other copyright owners and it is a condition of accessing publications that users recognise and abide by the legal requirements associated with these rights.

Take down policy

If you believe that this document breaches copyright please view our takedown policy at https://edshare.gcu.ac.uk/id/eprint/5179 for details of how to contact us. 
"Fatigue Alters the Pattern of Physical Activity Behaviour in Older Adults: Observational Analysis of Data from the Generation 100 Study" by Egerton T Helbostad JL, Stensvold D, Chastin S FM

Journal of Aging and Physical Activity

(C) 2016 Human Kinetics, Inc.

\section{Note: This article will be published in a forthcoming issue of the Journal of Aging and Physical Activity. This article appears here in its accepted, peer-reviewed form; it has not been copy edited, proofed, or formatted by the publisher.}

Section: Original Research

Article Title: Fatigue Alters the Pattern of Physical Activity Behaviour in Older Adults: Observational Analysis of Data from the Generation 100 Study

Authors: Thorlene Egerton ${ }^{1}$, Jorunn L Helbostad ${ }^{1,2}$, Dorthe Stensvold ${ }^{3}$ and Sebastien F M Chastin $^{4}$

Affiliations: ${ }^{1}$ Department of Neuroscience, Faculty of Medicine, Norwegian University of Science and Technology, Trondheim, Norway. ${ }^{2}$ Department of Clinical Services, St. Olav University Hospital, Trondheim, Norway. ${ }^{3}$ K.G. Jebsen Center of Exercise in Medicine at Department of Circulation and Medical Imaging, Faculty of Medicine, Norwegian University of Science and Technology, Trondheim, Norway. ${ }^{4}$ Institute of Applied Health Research, School of Health and Life Science, Glasgow Caledonian University, Glasgow, UK.

Journal: Journal of Aging and Physical Activity

Acceptance Date: March 28, 2016

(C)2016 Human Kinetics, Inc.

DOI: http://dx.doi.org/10.1123/japa.2015-0237 


\section{Fatigue alters the pattern of physical activity behaviour in older adults:}

\section{Observational analysis of data from the Generation 100 study}

Thorlene Egerton ${ }^{1}$, Jorunn L Helbostad ${ }^{1,2}$, Dorthe Stensvold ${ }^{3}$ and Sebastien F M Chastin ${ }^{4}$

${ }^{1}$ Department of Neuroscience, Faculty of Medicine, Norwegian University of Science and Technology, Trondheim, Norway.

${ }^{2}$ Department of Clinical Services, St. Olav University Hospital, Trondheim, Norway.

${ }^{3}$ K.G. Jebsen Center of Exercise in Medicine at Department of Circulation and Medical Imaging, Faculty of Medicine, Norwegian University of Science and Technology, Trondheim, Norway.

${ }^{4}$ Institute of Applied Health Research, School of Health and Life Science, Glasgow Caledonian University, Glasgow, UK.

Corresponding author details:

Thorlene Egerton, $\mathrm{PhD}^{1}$

Department of Neuroscience,

Faculty of Medicine,

Norwegian University of Science and Technology,

Trondheim, Norway

Email: thor@sutmap.com

Running title: Fatigue alters pattern of energy expenditure

\section{Email addresses:}

TE: thor@sutmap.com

JB: jorunn.helbostad@ntnu.no

DS: dorthe.stensvold@ntnu.no

SC: Sebastien.Chastin@gcu.ac.uk 
"Fatigue Alters the Pattern of Physical Activity Behaviour in Older Adults: Observational Analysis of Data from the Generation 100 Study" by Egerton T Helbostad JL, Stensvold D, Chastin S FM

Journal of Aging and Physical Activity

(C) 2016 Human Kinetics, Inc.

\section{Abstract}

Fatigue has been associated with reductions in daily activity of older people. Summary measures of daily physical activity provide limited understanding of how fatigue affects physical activity behaviour. This study examined the hour-by-hour energy expenditure estimated from accelerometry data in order to provide insight into physical activity behaviours of older people experiencing fatigue. Fatigued participants were matched to 'not fatigued' participants by age, sex and BMI. Each group consisted of 86 people with mean age 73.8 years (SD 2.0), BMI $26.5 \mathrm{~kg} \cdot \mathrm{m}^{-2}$ (SD 3.9) and 61\% female. The phase-space plot, constructed to express rate of change of average vertical axis counts per hour as a time series, showed fatigued participants deviated from the not fatigued participants during the morning period, when hour-by-hour activity was increasing. Older people who feel fatigued have a different morning activity pattern, which appears to lead to the lower overall levels of physical activity.

Key words: Asthenia, Ageing, Physical activity behaviour, Circadian rhythm, Bioenergetics 
"Fatigue Alters the Pattern of Physical Activity Behaviour in Older Adults: Observational Analysis of Data from the Generation 100 Study" by Egerton T Helbostad JL, Stensvold D, Chastin S FM

Journal of Aging and Physical Activity

(C) 2016 Human Kinetics, Inc.

\section{Introduction}

Fatigue is an under-recognised and poorly managed problem among older people. At least $25 \%$ of older people in primary care settings (Hickie et al., 1996) and up to $98 \%$ of older people in long-term care (Liao \& Ferrell, 2000) report experiencing unpleasant, debilitating fatigue. Fatigue may contribute to older people reducing the amount or intensity of physical activity they perform (Egerton, Chastin, Stensvold, \& Helbostad, 2015; Moreh, Jacobs, \& Stessman, 2010; Schrack et al., 2014), and may be a key component in a cycle of decline to dependency. Physical activity is well known to afford health and well-being benefits, and contributes to maintenance of independence and higher quality of life (Manini et al., 2009; Vagetti et al., 2014).

The subjective experience of fatigue (or tiredness or exhaustion) is a complex phenomenon with multiple possible causes (Alexander et al., 2010; Egerton, 2013). The condition is often largely unexplained. Subjective fatigue has been associated with a $15-20 \%$ reduction in daily activity, step count and the total time spent performing higher intensity activity in older people (Egerton et al., 2015). These summary measures of physical activity provide evidence of lower energy expenditure but limited understanding of how fatigue influences accumulation of physical activity. Exploration of the dynamic temporal patterns of accumulation of physical activity may offer additional insights, from which more targeted therapeutic solutions or intervention to promote increased activity in fatigued individuals can be developed (Arvidsson, Eriksson, Lonn, \& Sundquist, 2013; Taraldsen, Chastin, Riphagen, Vereijken, \& Helbostad, 2012). This study examined the hour-by-hour accumulation of physical activity measured by accelerometry in order to provide insight into the differences in physical activity accumulation patterns between those with and without fatigue.

\section{Methods}

Baseline data from the Generation 100 study were used (Stensvold et al., 2015). Generation 100 is an exercise intervention study carried out in Trondheim, Norway. Participants were all aged 70-77 years, recruited from the community and allocated to one of two exercise interventions or a 
"Fatigue Alters the Pattern of Physical Activity Behaviour in Older Adults: Observational Analysis of Data from the Generation 100 Study" by Egerton T Helbostad JL, Stensvold D, Chastin S FM

Journal of Aging and Physical Activity

(C) 2016 Human Kinetics, Inc.

control group. All participants born in 1936-1942 and resident in Trondheim were invited to volunteer for eligibility assessment and understood the study involved an exercise intervention. Exclusion criteria included cancer, cardiovascular disease or other test result that indicated participation in an exercise intervention was not appropriate or was contra-indicated (as determined by the research staff), dementia, chronic communicable infectious disease or participation in another research study. Compared with the 70-77 year old population in the catchment community, the included participants tended to be more active, have a higher level of education and reported better health (Stensvold et al., 2015). Baseline data were collected in 2012-13 and included demographics, self-reported health status information including a fatigue questionnaire (Fatigue Severity Scale (FSS)), cardiac risk factors, and physical performance measures. Ethical approval for the study was granted by the Norwegian Ethical Review Board for Medical and Health Research (REK 2012/381B and 2013/787B) and participants gave written informed consent.

Fatigue was measured using the Norwegian version of the 7-item FSS (Krupp, LaRocca, MuirNash, \& Steinberg, 1989; Lerdal, Wahl, Rustoen, Hanestad, \& Moum, 2005). The FSS items are shown in Table 1. The scale has response options from 1-7, which yields scores between 7 (no fatigue) and 49 (extreme fatigue). The psychometric properties of validity, reliability (Krupp et al., 1989) and cross-cultural validity for the Norwegian translation (Lerdal et al., 2005) have been reported. The FSS was originally validated in a chronic neurological illness population and has since been subjected to psychometric testing in a wide range of disease conditions and general population cohorts, with many of the samples including older adults (Johansson, Kottorp, Lee, Gay, \& Lerdal, 2014; Lerdal et al., 2005). The scale has been extensively used to measure subjective fatigue in studies, some of which have focussed on older adults (Soyuer \& Senol, 2011; Tennant, Takacs, Gau, Clark, \& Russ, 2012; Whitehead, 2009). The 7-item version excludes an item that specifically asks about activityrelated fatigue to improve its validity for measuring more chronic tiredness (Lerdal et al., 2011; Lerdal et al., 2005). Participants who responded to at least four items were included, and up to three 
"Fatigue Alters the Pattern of Physical Activity Behaviour in Older Adults: Observational Analysis of Data from the Generation 100 Study" by Egerton T Helbostad JL, Stensvold D, Chastin S FM

Journal of Aging and Physical Activity

(c) 2016 Human Kinetics, Inc.

missing items were imputed with the average score from answered items. A cut-off of $\geq 28$ is indicative of problematic fatigue (Valko, Bassetti, Bloch, Held, \& Baumann, 2008) and has been previously shown to be suitable for distinguishing patients with and without fatigue (Flachenecker et al., 2002; Krupp et al., 1989). Thus this cut off was used in this study to dichotomise those participants who were and were not fatigued. Eighty-six participants in the cohort reported $\geq 28$ on the FSS. These 'fatigued' participants were matched using Stata (StataCorp, LP, College Station, TX) to 'not fatigued' participants (FSS < 28) according to sex, age (same age in years) and BMI (closest available participant).

Several physical performance measures and self-reported health outcomes collected at baseline were reported in this study. These included $\mathrm{VO}_{\text {2peak }}$ as a measure of cardiorespiratory fitness, which was measured using standard $\mathrm{VO}_{2 \max }$ testing procedures (Egerton et al., 2015; Stensvold et al., 2015; Wisloff et al., 2007). As $\mathrm{VO}_{2 \max }$ was not achieved for all participants (64\%) the term $\mathrm{VO}_{2 \text { peak }}$ is used. Gait data was collected using a $6.7 \mathrm{~m}$ (5.5m active area) GAITRite ${ }^{\circledR}$ electronic walkway (CIR Systems Inc, Havertown, PA). Participants were asked to walk two passes each at their preferred or usual walking speed. The raw data was processed with the PKMAS $^{\circledR}$ (v507C413, ProtoKinetics, Havertown, PA) software and the calculated speed was averaged for the two walks (Egerton, Thingstad, \& Helbostad, 2014).

Self-report chronic conditions, history of cardiovascular disease, sleep, depression and prescription medication usage were recorded in the baseline questionnaire. The chronic conditions score was generated by asking "Do you have any long-term (at least 1 year) illnesses, injuries or problems of a physical or psychological nature that impairs your functioning in your daily life?" Participants were then asked to indicate whether their impairment was slight ( 1 point), moderate (2 points) or severe (3 points) in each category of mobility, physical illness or psychological illness. Total scores could range from 0-9. A positive history of cardiovascular disease was assigned when the participant reported having had myocardial infarction, angina pectoris, heart failure, or atrial 
"Fatigue Alters the Pattern of Physical Activity Behaviour in Older Adults: Observational Analysis of Data from the Generation 100 Study" by Egerton T Helbostad JL, Stensvold D, Chastin S FM

Journal of Aging and Physical Activity

(C) 2016 Human Kinetics, Inc.

fibrillation. A sleep score was calculated from three questions (1) "Have you had problems in getting to sleep in the last month?" (2) "During the last month, have you ever woken too early and not been able to get back to sleep?" and (3) "Do you feel sleepy during the day?", with four possible responses: $1=$ never or rarely, $2=$ now and then, or $3=$ several times per week. $A$ similar method has previously been reported (Sivertsen, Krokstad, Overland, \& Mykletun, 2009). Total scores ranged from 3-9. Depression was measured with the Hospital Anxiety and Depression Scale (Zigmond \& Snaith, 1983), which is a self-report rating scale of 14 items on a 4-point Likert scale (1 to 4). The scale was designed to measure the intensity of anxiety and depression symptoms ( 7 items for each subscale). For each subscale the score is the sum of the respective 7 items. The reliability and validity of the scale have been tested in several clinical and nonclinical studies (McCue, Buchanan, \& Martin, 2006). The depression subscale total was used for this study, with possible score range from 7 to 28 . Medication usage was measured by asking "How many prescription medications do you use in total?".

Physical activity was measured by ActiGraph GT3X (ActiGraph, Pensacola, FL) activity monitors worn on the right side using a belt around the waist. Participants were asked to wear the monitors continuously for seven consecutive days, apart from during water-based activities. The activity monitor records accelerations which are converted into activity counts that increase linearly with the magnitude of the acceleration. The activity counts reflect the intensity of bodily movement, thus the higher number of counts measured, the more active a person is (Hall, Howe, Rana, Martin, \& Morey, 2013). Total number of 'counts' was used for the outcome variable in this study to reflect total energy expending activity rather than imposing any external criteria such as intensity thresholds. Using intensity thresholds has been criticised for lack of validation in older adults (Gorman et al., 2014; Hall et al., 2013). The present study used only vertical axis data because most of the validation and calibration work has been done with only vertical axis data and the data will be more easily compared to other studies. Some evidence suggests that the vertical is indeed the most 
"Fatigue Alters the Pattern of Physical Activity Behaviour in Older Adults: Observational Analysis of Data from the Generation 100 Study" by Egerton T Helbostad JL, Stensvold D, Chastin S FM

Journal of Aging and Physical Activity

(C) 2016 Human Kinetics, Inc.

important axis (Hanggi, Phillips, \& Rowlands, 2013; Kelly et al., 2013), particularly for capturing ambulatory activity, which is the primary source of physical activity in older adults (Lord et al., 2011). Activity counts correlate well with energy expenditure when walking at different speeds and gradients (Hansen et al., 2013). Step counts can also be derived from vertical axis data using proprietary algorithms and while many studies have published these data (Arias-Palencia et al., 2015; Barreira, Harrington, Schuna, Tudor-Locke, \& Katzmarzyk, 2015; Ferguson, Rowlands, Olds, \& Maher, 2015) and validity of Actigraph step counts against direct observation has been demonstrated in some studies (Le Masurier, Lee, \& Tudor-Locke, 2004; Lee, Williams, Brown, \& Laurson, 2015), the accuracy has been shown to be suboptimal in others (Hickey, John, Sasaki, Mavilia, \& Freedson, 2015). Total daily step counts are reported in this study for descriptive purposes only. The 'Troiano 2007' wear time validation method was applied (Troiano, 2007). This is an established method of identifying data likely to be invalid due to device removal. In this method, continuous periods of zero counts for 60 minutes or more, with a tolerance of up to 2 minutes of up to 100 counts per minute (CPM) within the period, were defined as 'non-wear' and excluded from the analysis. Days were considered valid if there was a minimum of 10 hours of wear time, and a minimum of four valid days was required for inclusion of the participant.

Vertical axis counts were exported for each hour using Actilife software (Version 6.11.5, ActiGraph, Pensacola, FL). Counts per hour ( $\mathrm{CPH}$ ) was used to represent hourly energy expenditure of participants. For hours with less than 60 minutes of wear time, counts were divided by minutes of wear time and multiplied by 60 . For each participant, average $\mathrm{CPH}$ were calculated for each hour and then an average for each day. Average $\mathrm{CPH}$ for fatigued and not fatigued participants were plotted against time, for the whole cohort and separately for men and women, to show the within day pattern of energy expending activity. Sex differences have been found in vertical axis counts during free-living activity (Harris, Owen, Victor, Adams, \& Cook, 2009) and these differences have been shown to be independent of walking speed, step length or anthropometrics (Van Domelen et al., 
"Fatigue Alters the Pattern of Physical Activity Behaviour in Older Adults: Observational Analysis of Data from the Generation 100 Study" by Egerton T Helbostad JL, Stensvold D, Chastin S FM

Journal of Aging and Physical Activity

(C) 2016 Human Kinetics, Inc.

2014). Therefore it was considered important to explore whether the pattern of activity behaviour differs between older men and older women.

Data analysis followed a dynamic systems approach to understand differences in temporal evolution of energy expending activity between fatigued and not fatigued older adults. The CPH time series were analysed using phase-space plot charting the change in hourly energy expending activity (d1CPH) against the energy expending activity (CPH) in the previous hour (Kantz \& Schreiber, 2004). Phase-space plots were generated using matlab R12.b with smooth interpolation between data points. The phase-space plot enables identification of differences in the rate of changes in amount of energy expending activity over time. When the hour-by-hour energy expending activity is increasing (an acceleration phase), the $\mathrm{d} 1 \mathrm{CPH}$ is positive. When the hourly activity is decreasing with each passing hour, the $\mathrm{d} 1 \mathrm{CPH}$ is negative. For periods of the day when the hour-by-hour rate of change is steady, either increasing or decreasing, these periods can be fitted to a linear regression line and the slopes compared statistically with t-tests.

\section{Results}

Each group consisted of 86 people with mean age 73.8 years (SD 2.0), BMI $26.5 \mathrm{~kg} \cdot \mathrm{m}^{-2}$ (SD 3.9) and 52 (61\%) were female. Participant selection details are shown in Figure 1 and descriptive information in Table 2. The fatigued participants had lower cardiorespiratory fitness (VO2max), slower gait speed, more chronic conditions, were more likely to have a history of cardiovascular disease, had poorer sleep, and higher levels of depression, but there was no statistically significant difference in number of prescription medications. There was no difference in number of valid days of activity recording or wear time per day between fatigued and not fatigued participants. Mean valid days was 7.4 days (SD 1.6) for fatigued and 7.7 days (SD 2.7) for not fatigued, and mean wear time per day was 18.6 hours (SD 1.8) for fatigued and 19.0 hours (SD 1.6) for not fatigued ( $p>0.05$ ). The average minutes of valid data (wear time) per hour across all hours and all participants was 52.3 minutes for fatigued and 53.4 minutes for not fatigued participants. The minutes of valid data per 
"Fatigue Alters the Pattern of Physical Activity Behaviour in Older Adults: Observational Analysis of Data from the Generation 100 Study" by Egerton T Helbostad JL, Stensvold D, Chastin S FM

Journal of Aging and Physical Activity

(C) 2016 Human Kinetics, Inc.

hour varied with the lowest average for 00:00-01:00hrs at 41.6 minutes, and the highest for 12:0013:00hrs at 58.8 minutes. The daytime hours from 06:00-20:00hrs all had an average of over 50 minutes of valid data per hour. Loss of valid data could be due to correctly classified non-wear if the participant removed the device, or incorrectly classified non-wear which may happen during sleep periods and therefore predominantly affects hours between midnight and 06:00hrs. As expected, a difference in daily energy expenditure was evident: 180 CPM (SD 72) versus 217 CPM (SD 78) for fatigued and not fatigued respectively $(p=0.002)$. Similarly there was a difference in daily step count derived from the ActiGraph data: 5466 steps/day (SD 2138) versus 6604 steps/day (SD 1958) ( $<<$ $0.001)$.

Figure 2 shows the hourly pattern of accumulation of activity for fatigued and not fatigued older people and for each sex separately. In both men and women the peak hour of activity was later and lower for the fatigued participants. Figure 3 is the phase-space plot showing a deviation between the groups in the dynamics of energy expenditure. Above $10000 \mathrm{CPH}$ the fatigued group does not sustain the same rate of energy expenditure during the period of positive rate of change (acceleration phase), leading to a different peak of energy expenditure. Figure 4 shows the linear regression lines for the morning (acceleration phase) from 06:00hrs to 12:00hrs, and the afternoon/evening (deceleration phase) from 13:00hrs to 20:00hrs. The difference in slopes of the regression lines for fatigued and not fatigued participants was significant for the morning period $(p=0.003)$ but not for the afternoon/evening period $(p=0.475)$.

\section{Discussion}

A pattern of daily accumulation of activity, whereby hourly activity increases during the morning, peaks around the middle of the day / early afternoon, and decreases hour-by-hour during the afternoon and evening, was found for both fatigued and not fatigued participants, and for both men and women. Differences were found in the phase-space plot depicting rate of energy expending activity between the groups. The difference in dynamics appears to depend on the time of the day or 
"Fatigue Alters the Pattern of Physical Activity Behaviour in Older Adults: Observational Analysis of Data from the Generation 100 Study" by Egerton T Helbostad JL, Stensvold D, Chastin S FM

Journal of Aging and Physical Activity

(C) 2016 Human Kinetics, Inc.

whether rate was accelerating or decelerating. The rate of increase of energy expending activity was reduced during the morning period for fatigued people compared with not fatigued people. At a certain level of hourly activity (around $10000 \mathrm{CPH}$ ) the fatigued group, despite apparently being capable of reaching higher hourly activity levels (as evidenced by the higher levels later in the day), did not increase at the same rate as the not fatigued people.

While at an individual level, hourly energy expending activity is highly variable within and between participants, once sufficient numbers of participants are combined, the shape of the hourby-hour activity plot becomes surprisingly simple. Activity increases with each hour until a peak, and then gradually declines hour-by-hour until the evening. This temporal pattern has been found in some previous research studies (Arvidsson et al., 2013; Cooper, Page, Fox, \& Misson, 2000; Martin et al., 2014; Page et al., 2005; Schrack et al., 2014; Steeves, Murphy, Zipunnikov, Strath, \& Harris, 2015), but not others (Cooper et al., 2000; Page et al., 2005; Tanaka, Kawamata, Gen-No, Nose, \& Kawamata, 2015). The pattern seems to emerge in studies with people who are not constrained by work or school, such as older people or in studies where the data is collected on weekend days, and in studies with larger numbers. Work appears to stimulate activity such that when older people are unconstrained by work, they become less active (Schrack et al., 2014). The data are suggestive of an underlying universal dynamical (within-day) energy expenditure law that is frequently over-ridden at an individual level depending on the many internal and external influences driving our need and desire to be physically active.

The progressive hour-by-hour increase/decrease is intriguing. The pattern does not fit well with the notion of pacing, where a steady state of activity would be maintained throughout the day, as determined by knowledge of the tasks required, and energy and time available (Noakes, 2012). Activity at individual level is known to be highly variable and accumulated in shorter bouts (Chastin et al., 2009; Levine et al., 2008; Matthews et al., 2008). The pattern reflects hourly activity averaged over multiple participants and multiple days, but may expose the existence of an underlying activity 
"Fatigue Alters the Pattern of Physical Activity Behaviour in Older Adults: Observational Analysis of Data from the Generation 100 Study" by Egerton T Helbostad JL, Stensvold D, Chastin S FM

Journal of Aging and Physical Activity

(C) 2016 Human Kinetics, Inc.

driver. Multiple compelling factors may be simultaneously involved, whereby each hour of activity is dependent upon the previous hour of activity, plus circadian cycles in several biological systems such as melatonin or cortisol levels (Gomersall, Rowlands, English, Maher, \& Olds, 2013). Such biological determinants of activity have received less attention than physical, psychosocial and environmental determinants of physical activity. Yet evidence from human and animal studies suggests several possible genetic and metabolic mechanisms, such as neurohumeral processes, a hypothalamic feedback loop to dampen down voluntary activity, and the dopaminergic and endocannabinoid systems, may play a part in controlling energy expenditure through physical activity (Eisenmann \& Wickel, 2009; Garland et al., 2011; Thorburn \& Proietto, 2000). Within day fluctuations have been documented for various physiological variables (Trine \& Morgan, 1995). These include body temperature, heart rate, blood pressure, cortisol, adrenaline (epinephrine) and noradrenaline (norepinephrine), under resting and active conditions (Trine \& Morgan, 1995). For example, exercise heart rate is lowest in the morning and peaks during the afternoon (Trine \& Morgan, 1995). Interestingly, perceived effort of walking was found not to be associated with energy cost of walking in older adults (Julius, Brach, Wert, \& VanSwearingen, 2012), implying that perceived effort may be related to physiological variables rather than to physical ability. Perceived effort is a major component of self-reported fatigue (Egerton, 2013), and instantaneous perceived effort during a standardized task (fatigability) has been found to be directly related to self-selected gait speed and self-reported mobility ability (Simonsick, Schrack, Glynn, \& Ferrucci, 2014). The extent to which physiological or other psychological variables, such as perception of effort, mood states and anxiety, are subject to within day rhythms and directly or indirectly drive physical activity, perhaps through sensations of energy or fatigue, are lines of inquiry for future research.

Fatigue appeared to lead to a slower rate of change in hourly activity, during the morning, or during the phase of increasing rate, resulting in the reduced total amount of activity seen in all the volumetric activity outcomes reported. We did not find that fatigued people spent less of the day 
"Fatigue Alters the Pattern of Physical Activity Behaviour in Older Adults: Observational Analysis of Data from the Generation 100 Study" by Egerton T Helbostad JL, Stensvold D, Chastin S FM

Journal of Aging and Physical Activity

(c) 2016 Human Kinetics, Inc.

active or ceased activity earlier in the day. The timings of the morning rise and afternoon fall in hourly counts were similar in both groups. An alteration in energy balance, or the perception of energy balance, hour-by-hour, or perhaps minute-by-minute, may be the primary factor limiting activity performance (Kluger, Krupp, \& Enoka, 2013). Previous research has shown age-related decreases in physical activity (Martin et al., 2014; Schrack et al., 2014). Lack of available energy has been proposed as the mediator in the decline, and fatigue as the mechanism in this age-related difference (Schrack et al., 2014). Actual or perceived lack of available energy may be a result of the higher resting energy expenditure and/or inflammation that occur in older people with multiple chronic diseases (Fabbri, An, Schrack, et al., 2015; Fabbri, An, Zoli, et al., 2015). The hypothesis was tested by Schrager et al (Schrager, Schrack, Simonsick, \& Ferrucci, 2014) who determined the participants' 'available energy' from a walking protocol and showed that 'available energy' was associated with lower physical activity levels. Our data further support this hypothesis. They also found that among those with the lowest cardiorespiratory fitness, this association was even stronger. It is clear that the mechanisms responsible for the perceptions of energy and fatigue need to be determined in order to derive solutions that address the difficulty older people in general, and even more so older people experiencing high levels of fatigue, appear to have in achieving adequate levels of daily physical activity.

The main limitations of the study are the subjectivity of the fatigue questionnaire, which is a problem with all self-report measures, and the lack of specificity in the fatigue questionnaire. It is now known that there are several subtypes of fatigue caused by a range of different problems including tiredness from sleep disorders, directly from a bout of physical activity or from certain neurological or inflammatory diseases and cancer. The data available showed the fatigued group had lower cardiovascular fitness, slower gait speed, more self-reported chronic conditions, were more likely to have a history of cardiovascular disease, had worse sleep and higher depression scores. All of these conditions could explain the fatigue or confound the association between fatigue and 
"Fatigue Alters the Pattern of Physical Activity Behaviour in Older Adults: Observational Analysis of Data from the Generation 100 Study" by Egerton T Helbostad JL, Stensvold D, Chastin S FM

Journal of Aging and Physical Activity

(C) 2016 Human Kinetics, Inc.

physical activity. The fatigued participants in this study may have had different combinations of causes of their fatigue symptoms and not all causes of fatigue will necessarily have the same association with physical activity. This study does not try to relate the altered activity pattern to anything other than the subjectively reported experience of fatigue. Future research should determine whether different fatigue causes, or other related conditions such as depression, lead to different alterations in energy expending activity patterns. Of note, the participants in this study all met the study inclusion/exclusion criteria, were deemed by research staff to be physically capable of participating in an exercise intervention and volunteered for a study with an exercise component.

There are also important methodological limitations with the activity measurement. Reduced minutes/hour of valid data may lead to an under estimation of activity if lost minutes included higher than average activity such as swimming, or an overestimation if lost minutes had lower than average activity for example if sedentary behaviour is miscategorised as non-wear (typically during night time). Miscategorisation of non-wear vs sedentary behaviour at night would not noticeably affect our findings, and the low level of data loss during daytime hours increases confidence in the results.

\section{Conclusion}

This observational study showed that fatigue affects older people's rate of increasing energy expending activity during the morning. This apparently different morning activity pattern appears to lead to the lower overall levels of physical activity. Limited available energy for physical activity may lead to a fatigue burden that has an hour-by-hour cumulative effect on activity. The question now is how to use the knowledge of alteration in the rate of increase of activity as a target of therapeutic interventions in order to promote greater physical activity among both healthy and fatigued older people. Interventions targeting perceptions of energy and fatigue may be worthwhile and there may be times of the day when physical activity interventions have more effect. For example, targeting the middle of day for physical activities or exercise may help older people experiencing fatigue to 
"Fatigue Alters the Pattern of Physical Activity Behaviour in Older Adults: Observational Analysis of Data from the Generation 100 Study" by Egerton T Helbostad JL, Stensvold D, Chastin S FM

Journal of Aging and Physical Activity

(C) 2016 Human Kinetics, Inc.

achieve long term higher levels of activity. However, clearly more needs to be understood about the mechanisms involved in the perceptions of available energy and the biological mechanisms that drive within-day physical activity.

\section{Competing interests}

The authors declare that they have no competing interests

\section{Authors' contributions}

TE conceived and designed the study, processed, analysed and interpreted the data, and drafted the manuscript. DS and JH were involved in revising the manuscript critically, and DS was responsible for the data collection. SC made substantial contributions to conception and design, interpretation of data, and revising the manuscript. All authors have read and approved the final version of the manuscript.

\section{Acknowledgements and funding sources}

The authors wish to thank the study staff and participants of the Generation 100 study.

The work was supported by the K.G. Jebsen Center for Exercise in Medicine; the Health Authorities of Mid-Norway; Norwegian Women`s Health Association [TE]; and the Norwegian Extra Foundation for Health and Rehabilitation through EXTRA funds [TE]. 
"Fatigue Alters the Pattern of Physical Activity Behaviour in Older Adults: Observational Analysis of Data from the Generation 100 Study" by Egerton T Helbostad JL, Stensvold D, Chastin S FM

Journal of Aging and Physical Activity

(c) 2016 Human Kinetics, Inc.

\section{References}

Alexander, N. B., Taffet, G. E., Horne, F. M., Eldadah, B. A., Ferrucci, L., Nayfield, S., \& Studenski, S. (2010). Bedside-to-Bench conference: research agenda for idiopathic fatigue and aging. J Am Geriatr Soc, 58(5), 967-975. doi: 10.1111/j.1532-5415.2010.02811.x

Arias-Palencia, N. M., Solera-Martinez, M., Gracia-Marco, L., Silva, P., Martinez-Vizcaino, V., CaneteGarcia-Prieto, J., \& Sanchez-Lopez, M. (2015). Levels and Patterns of Objectively Assessed Physical Activity and Compliance with Different Public Health Guidelines in University Students. PLoS One, 10(11), e0141977. doi: 10.1371/journal.pone.0141977

Arvidsson, D., Eriksson, U., Lonn, S. L., \& Sundquist, K. (2013). Neighborhood walkability, income, and hour-by-hour physical activity patterns. Med Sci Sports Exerc, 45(4), 698-705. doi: 10.1249/MSS.0b013e31827a1d05

Barreira, T. V., Harrington, D. M., Schuna, J. M., Jr., Tudor-Locke, C., \& Katzmarzyk, P. T. (2015). Pattern changes in step count accumulation and peak cadence due to a physical activity intervention. J Sci Med Sport. doi: 10.1016/j.jsams.2015.01.008

Chastin, S. F., Dall, P. M., Tigbe, W. W., Grant, M. P., Ryan, C. G., Rafferty, D., \& Granat, M. H. (2009). Compliance with physical activity guidelines in a group of UK-based postal workers using an objective monitoring technique. Eur J Appl Physiol, 106(6), 893-899. doi: 10.1007/s00421009-1090-x

Cooper, A. R., Page, A., Fox, K. R., \& Misson, J. (2000). Physical activity patterns in normal, overweight and obese individuals using minute-by-minute accelerometry. Eur $J$ Clin Nutr, 54(12), 887-894.

Egerton, T. (2013). Self-reported aging-related fatigue: a concept description and its relevance to physical therapist practice. Phys Ther, 93(10), 1403-1413. doi: 10.2522/ptj.20130011

Egerton, T., Chastin, S. F. M., Stensvold, D., \& Helbostad, J. L. (2015). Fatigue may contribute to reduced physical activity among older people: An observational study. J Gerontol A Biol Sci Med Sci, 1-8. doi: 10.1093/gerona/glv150

Egerton, T., Thingstad, P., \& Helbostad, J. L. (2014). Comparison of programs for determining temporal-spatial gait variables from instrumented walkway data: PKmas versus GAITRite. BMC Res Notes, 7, 542. doi: 10.1186/1756-0500-7-542

Eisenmann, J. C., \& Wickel, E. E. (2009). The biological basis of physical activity in children: revisited. Pediatr Exerc Sci, 21(3), 257-272.

Fabbri, E., An, Y., Schrack, J. A., Gonzalez-Freire, M., Zoli, M., Simonsick, E. M., . . Ferrucci, L. (2015). Energy Metabolism and the Burden of Multimorbidity in Older Adults: Results From the Baltimore Longitudinal Study of Aging. J Gerontol A Biol Sci Med Sci, 70(11), 1297-1303. doi: 10.1093/gerona/glu209

Fabbri, E., An, Y., Zoli, M., Simonsick, E. M., Guralnik, J. M., Bandinelli, S., . . Ferrucci, L. (2015). Aging and the burden of multimorbidity: associations with inflammatory and anabolic hormonal biomarkers. J Gerontol A Biol Sci Med Sci, 70(1), 63-70. doi: 10.1093/gerona/glu127 
"Fatigue Alters the Pattern of Physical Activity Behaviour in Older Adults: Observational Analysis of Data from the Generation 100 Study" by Egerton T Helbostad JL, Stensvold D, Chastin S FM

Journal of Aging and Physical Activity

(C) 2016 Human Kinetics, Inc.

Ferguson, T., Rowlands, A. V., Olds, T., \& Maher, C. (2015). The validity of consumer-level, activity monitors in healthy adults worn in free-living conditions: a cross-sectional study. Int J Behav Nutr Phys Act, 12, 42. doi: 10.1186/s12966-015-0201-9

Flachenecker, P., Kumpfel, T., Kallmann, B., Gottschalk, M., Grauer, O., Rieckmann, P., ... Toyka, K. V. (2002). Fatigue in multiple sclerosis: a comparison of different rating scales and correlation to clinical parameters. Mult Scler, 8(6), 523-526.

Garland, T., Jr., Schutz, H., Chappell, M. A., Keeney, B. K., Meek, T. H., Copes, L. E., . . Eisenmann, J. C. (2011). The biological control of voluntary exercise, spontaneous physical activity and daily energy expenditure in relation to obesity: human and rodent perspectives. J Exp Biol, 214(Pt 2), 206-229. doi: 10.1242/jeb.048397

Gomersall, S. R., Rowlands, A. V., English, C., Maher, C., \& Olds, T. S. (2013). The ActivityStat hypothesis: the concept, the evidence and the methodologies. Sports Med, 43(2), 135-149. doi: $10.1007 / \mathrm{s} 40279-012-0008-7$

Gorman, E., Hanson, H. M., Yang, P. H., Khan, K. M., Liu-Ambrose, T., \& Ashe, M. C. (2014). Accelerometry analysis of physical activity and sedentary behavior in older adults: a systematic review and data analysis. Eur Rev Aging Phys Act, 11, 35-49. doi: 10.1007/s11556013-0132-x

Hall, K. S., Howe, C. A., Rana, S. R., Martin, C. L., \& Morey, M. C. (2013). METs and accelerometry of walking in older adults: standard versus measured energy cost. Med Sci Sports Exerc, 45(3), 574-582. doi: 10.1249/MSS.0b013e318276c73c

Hanggi, J. M., Phillips, L. R., \& Rowlands, A. V. (2013). Validation of the GT3X ActiGraph in children and comparison with the GT1M ActiGraph. J Sci Med Sport, 16(1), 40-44. doi: 10.1016/j.jsams.2012.05.012

Hansen, B. H., Bortnes, I., Hildebrand, M., Holme, I., Kolle, E., \& Anderssen, S. A. (2013). Validity of the ActiGraph GT1M during walking and cycling. J Sports Sci. doi: 10.1080/02640414.2013.844347

Harris, T. J., Owen, C. G., Victor, C. R., Adams, R., \& Cook, D. G. (2009). What factors are associated with physical activity in older people, assessed objectively by accelerometry? Br J Sports Med, 43(6), 442-450. doi: 10.1136/bjsm.2008.048033

Hickey, A., John, D., Sasaki, J. E., Mavilia, M., \& Freedson, P. (2015). Validity of Activity Monitor Step Detection is Related to Movement Patterns. J Phys Act Health. doi: 10.1123/jpah.2015-0203

Hickie, I. B., Hooker, A. W., Hadzi-Pavlovic, D., Bennett, B. K., Wilson, A. J., \& Lloyd, A. R. (1996). Fatigue in selected primary care settings: sociodemographic and psychiatric correlates. Med J Aust, 164(10), 585-588.

Johansson, S., Kottorp, A., Lee, K. A., Gay, C. L., \& Lerdal, A. (2014). Can the Fatigue Severity Scale 7item version be used across different patient populations as a generic fatigue measure--a comparative study using a Rasch model approach. Health Qual Life Outcomes, 12, 24. doi: $10.1186 / 1477-7525-12-24$

Julius, L. M., Brach, J. S., Wert, D. M., \& VanSwearingen, J. M. (2012). Perceived effort of walking: relationship with gait, physical function and activity, fear of falling, and confidence in 
"Fatigue Alters the Pattern of Physical Activity Behaviour in Older Adults: Observational Analysis of Data from the Generation 100 Study" by Egerton T Helbostad JL, Stensvold D, Chastin S FM

Journal of Aging and Physical Activity

(c) 2016 Human Kinetics, Inc.

walking in older adults with mobility limitations. Phys Ther, 92(10), 1268-1277. doi: 10.2522/ptj.20110326

Kantz, H., \& Schreiber, T. (2004). Nonlinear time series analysis (2nd ed.). Cambridge, UK: Cambridge University Press.

Kelly, L. A., McMillan, D. G., Anderson, A., Fippinger, M., Fillerup, G., \& Rider, J. (2013). Validity of actigraphs uniaxial and triaxial accelerometers for assessment of physical activity in adults in laboratory conditions. BMC Med Phys, 13(1), 5. doi: 10.1186/1756-6649-13-5

Kluger, B. M., Krupp, L. B., \& Enoka, R. M. (2013). Fatigue and fatigability in neurologic illnesses: proposal for a unified taxonomy. Neurology, 80(4), 409-416. doi: 10.1212/WNL.0b013e31827f07be

Krupp, L. B., LaRocca, N. G., Muir-Nash, J., \& Steinberg, A. D. (1989). The fatigue severity scale. Application to patients with multiple sclerosis and systemic lupus erythematosus. Arch Neurol, 46(10), 1121-1123.

Le Masurier, G. C., Lee, S. M., \& Tudor-Locke, C. (2004). Motion sensor accuracy under controlled and free-living conditions. Med Sci Sports Exerc, 36(5), 905-910.

Lee, J. A., Williams, S. M., Brown, D. D., \& Laurson, K. R. (2015). Concurrent validation of the Actigraph gt $3 \mathrm{x}+$, Polar Active accelerometer, Omron HJ-720 and Yamax Digiwalker SW-701 pedometer step counts in lab-based and free-living settings. J Sports Sci, 33(10), 991-1000. doi: 10.1080/02640414.2014.981848

Lerdal, A., Kottorp, A., Gay, C., Aouizerat, B. E., Portillo, C. J., \& Lee, K. A. (2011). A 7-item version of the fatigue severity scale has better psychometric properties among HIV-infected adults: an application of a Rasch model. Qual Life Res, 20(9), 1447-1456. doi: 10.1007/s11136-0119877-8

Lerdal, A., Wahl, A., Rustoen, T., Hanestad, B. R., \& Moum, T. (2005). Fatigue in the general population: a translation and test of the psychometric properties of the Norwegian version of the fatigue severity scale. Scand J Public Health, 33(2), 123-130. doi: $10.1080 / 14034940410028406$

Levine, J. A., McCrady, S. K., Lanningham-Foster, L. M., Kane, P. H., Foster, R. C., \& Manohar, C. U. (2008). The role of free-living daily walking in human weight gain and obesity. Diabetes, 57(3), 548-554. doi: 10.2337/db07-0815

Liao, S., \& Ferrell, B. A. (2000). Fatigue in an older population. J Am Geriatr Soc, 48(4), 426-430.

Lord, S., Chastin, S. F., McInnes, L., Little, L., Briggs, P., \& Rochester, L. (2011). Exploring patterns of daily physical and sedentary behaviour in community-dwelling older adults. Age Ageing, 40(2), 205-210. doi: 10.1093/ageing/afq166

Manini, T. M., Everhart, J. E., Patel, K. V., Schoeller, D. A., Cummings, S., Mackey, D. C., . . Body Composition, S. (2009). Activity energy expenditure and mobility limitation in older adults: differential associations by sex. Am J Epidemiol, 169(12), 1507-1516. doi: 10.1093/aje/kwp069

Martin, K. R., Koster, A., Murphy, R. A., Van Domelen, D. R., Hung, M. Y., Brychta, R. J., . . Harris, T. B. (2014). Changes in daily activity patterns with age in U.S. men and women: National 
"Fatigue Alters the Pattern of Physical Activity Behaviour in Older Adults: Observational Analysis of Data from the Generation 100 Study" by Egerton T Helbostad JL, Stensvold D, Chastin S FM

Journal of Aging and Physical Activity

(c) 2016 Human Kinetics, Inc.

Health and Nutrition Examination Survey 2003-04 and 2005-06. J Am Geriatr Soc, 62(7), 1263-1271. doi: 10.1111/jgs.12893

Matthews, C. E., Chen, K. Y., Freedson, P. S., Buchowski, M. S., Beech, B. M., Pate, R. R., \& Troiano, R. P. (2008). Amount of time spent in sedentary behaviors in the United States, 2003-2004. Am J Epidemiol, 167(7), 875-881. doi: 10.1093/aje/kwm390

McCue, P., Buchanan, T., \& Martin, C. R. (2006). Screening for psychological distress using internet administration of the Hospital Anxiety and Depression Scale (HADS) in individuals with chronic fatigue syndrome. Br J Clin Psychol, 45(Pt 4), 483-498. doi: 10.1348/014466505X82379

Moreh, E., Jacobs, J. M., \& Stessman, J. (2010). Fatigue, function, and mortality in older adults. J Gerontol A Biol Sci Med Sci, 65(8), 887-895. doi: 10.1093/gerona/glq064

Noakes, T. D. (2012). Fatigue is a Brain-Derived Emotion that Regulates the Exercise Behavior to Ensure the Protection of Whole Body Homeostasis. Front Physiol, 3, 82. doi: 10.3389/fphys.2012.00082

Page, A., Cooper, A. R., Stamatakis, E., Foster, L. J., Crowne, E. C., Sabin, M., \& Shield, J. P. (2005). Physical activity patterns in nonobese and obese children assessed using minute-by-minute accelerometry. Int J Obes (Lond), 29(9), 1070-1076. doi: 10.1038/sj.ijo.0802993

Schrack, J. A., Zipunnikov, V., Goldsmith, J., Bai, J., Simonsick, E. M., Crainiceanu, C., \& Ferrucci, L. (2014). Assessing the "physical cliff": detailed quantification of age-related differences in daily patterns of physical activity. J Gerontol A Biol Sci Med Sci, 69(8), 973-979. doi: 10.1093/gerona/glt199

Schrager, M. A., Schrack, J. A., Simonsick, E. M., \& Ferrucci, L. (2014). Association between energy availability and physical activity in older adults. Am J Phys Med Rehabil, 93(10), 876-883. doi: 10.1097/PHM.0000000000000108

Simonsick, E. M., Schrack, J. A., Glynn, N. W., \& Ferrucci, L. (2014). Assessing fatigability in mobilityintact older adults. J Am Geriatr Soc, 62(2), 347-351. doi: 10.1111/jgs.12638

Sivertsen, B., Krokstad, S., Overland, S., \& Mykletun, A. (2009). The epidemiology of insomnia: associations with physical and mental health. The HUNT-2 study. J Psychosom Res, 67(2), 109-116. doi: 10.1016/j.jpsychores.2009.05.001

Soyuer, F., \& Senol, V. (2011). Functional outcome and depression in the elderly with or without fatigue. Arch Gerontol Geriatr, 53(2), e164-167. doi: 10.1016/j.archger.2010.08.006

Steeves, J. A., Murphy, R. A., Zipunnikov, V., Strath, S. J., \& Harris, T. B. (2015). Women Workers and Women at Home Are Equally Inactive: NHANES 2003-2006. Med Sci Sports Exerc, 47(8), 1635-1642. doi: 10.1249/MSS.0000000000000582

Stensvold, D., Viken, H., Rognmo, O., Skogvoll, E., Steinshamn, S., Vatten, L. J., . . Wisloff, U. (2015). A randomised controlled study of the long-term effects of exercise training on mortality in elderly people: study protocol for the Generation 100 study. BMJ Open, 5(2), e007519. doi: 10.1136/bmjopen-2014-007519 
"Fatigue Alters the Pattern of Physical Activity Behaviour in Older Adults: Observational Analysis of Data from the Generation 100 Study" by Egerton T Helbostad JL, Stensvold D, Chastin S FM

Journal of Aging and Physical Activity

(C) 2016 Human Kinetics, Inc.

Tanaka, H., Kawamata, T., Gen-No, H., Nose, H., \& Kawamata, M. (2015). Evaluation of the physical activity of anesthesiologists in the operating room during daily work using a triaxial accelerometer. Arch Environ Occup Health, 70(2), 77-80. doi:

10.1080/19338244.2013.778809

Taraldsen, K., Chastin, S. F., Riphagen, II, Vereijken, B., \& Helbostad, J. L. (2012). Physical activity monitoring by use of accelerometer-based body-worn sensors in older adults: a systematic literature review of current knowledge and applications. Maturitas, 71(1), 13-19. doi: 10.1016/j.maturitas.2011.11.003

Tennant, K. F., Takacs, S. E., Gau, J. T., Clark, B. C., \& Russ, D. W. (2012). A preliminary study of symptomatic fatigue in rural older adults. Aging Clin Exp Res, 24(4), 324-330. doi: $10.3275 / 8054$

Thorburn, A. W., \& Proietto, J. (2000). Biological determinants of spontaneous physical activity. Obes Rev, 1(2), 87-94.

Trine, M. R., \& Morgan, W. P. (1995). Influence of time of day on psychological responses to exercise. A review. Sports Med, 20(5), 328-337.

Troiano, R. P. (2007). Large-scale applications of accelerometers: new frontiers and new questions. Med Sci Sports Exerc, 39(9), 1501. doi: 10.1097/mss.0b013e318150d42e

Vagetti, G. C., Barbosa Filho, V. C., Moreira, N. B., Oliveira, V. D., Mazzardo, O., \& Campos, W. D. (2014). Association between physical activity and quality of life in the elderly: a systematic review, 2000-2012. Rev Bras Psiquiatr, 36(1), 76-88. doi: 10.1590/1516-4446-2012-0895

Valko, P. O., Bassetti, C. L., Bloch, K. E., Held, U., \& Baumann, C. R. (2008). Validation of the fatigue severity scale in a Swiss cohort. Sleep, 31(11), 1601-1607.

Van Domelen, D. R., Caserotti, P., Brychta, R. J., Harris, T. B., Patel, K. V., Chen, K. Y., . . Koster, A. (2014). Is there a sex difference in accelerometer counts during walking in older adults? $J$ Phys Act Health, 11(3), 626-637. doi: 10.1123/jpah.2012-0050

Whitehead, L. (2009). The measurement of fatigue in chronic illness: a systematic review of unidimensional and multidimensional fatigue measures. J Pain Symptom Manage, 37(1), 107-128. doi: 10.1016/j.jpainsymman.2007.08.019

Wisloff, U., Stoylen, A., Loennechen, J. P., Bruvold, M., Rognmo, O., Haram, P. M., . . Skjaerpe, T. (2007). Superior cardiovascular effect of aerobic interval training versus moderate continuous training in heart failure patients: a randomized study. Circulation, 115(24), 30863094. doi: 10.1161/CIRCULATIONAHA.106.675041

Zigmond, A. S., \& Snaith, R. P. (1983). The hospital anxiety and depression scale. Acta Psychiatr Scand, 67(6), 361-370. 


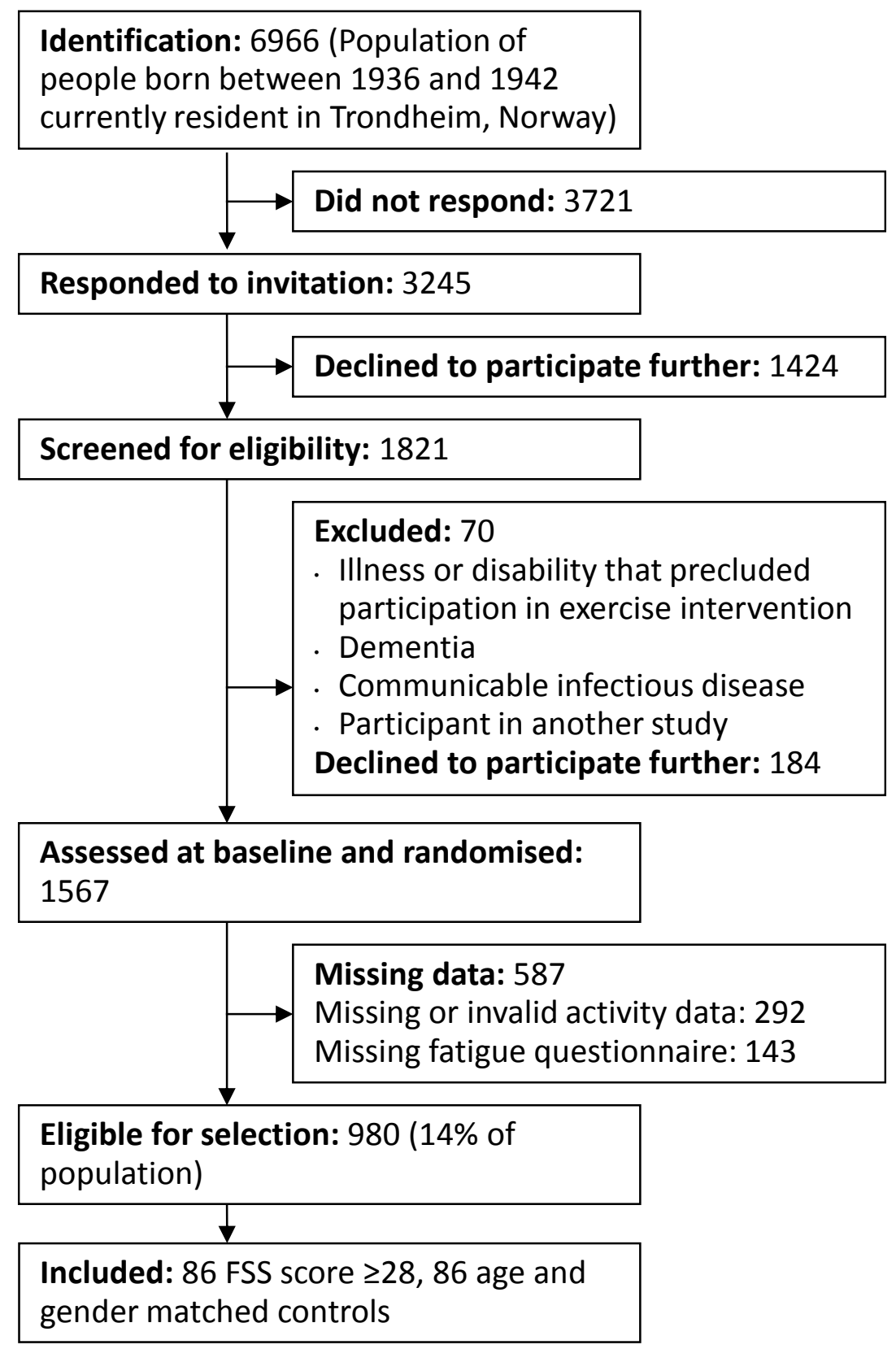

Figure 1. Flow diagram of participant selection. 
"Fatigue Alters the Pattern of Physical Activity Behaviour in Older Adults: Observational Analysis of Data from the Generation 100 Study" by Egerton T Helbostad JL, Stensvold D, Chastin S FM

Journal of Aging and Physical Activity

(C) 2016 Human Kinetics, Inc.

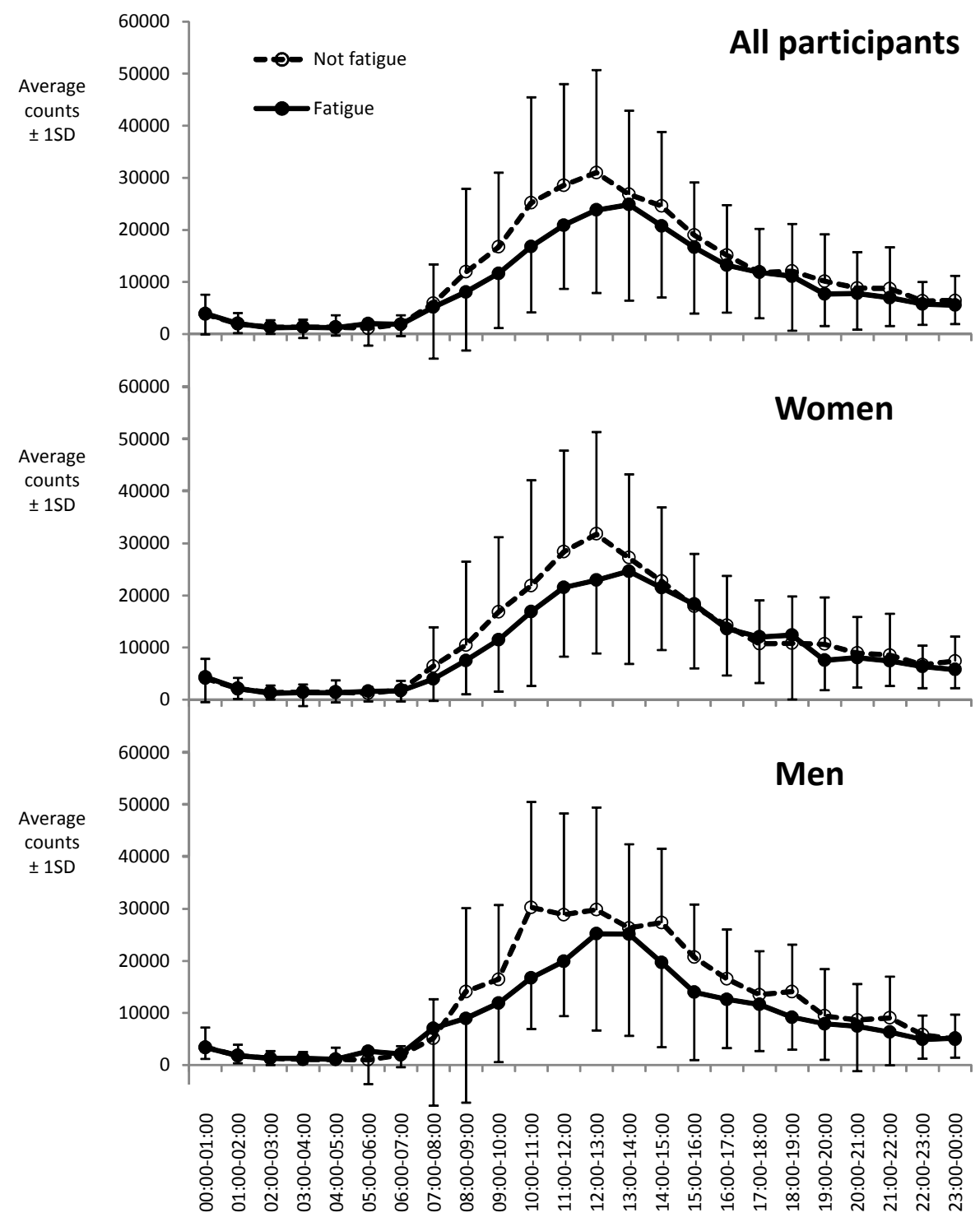

Figure 2. Hour-by-hour energy expenditure for fatigued and not fatigued older people and for each sex separately. 
"Fatigue Alters the Pattern of Physical Activity Behaviour in Older Adults: Observational Analysis of Data from the Generation 100 Study" by Egerton T Helbostad JL, Stensvold D, Chastin S FM Journal of Aging and Physical Activity

(C) 2016 Human Kinetics, Inc.

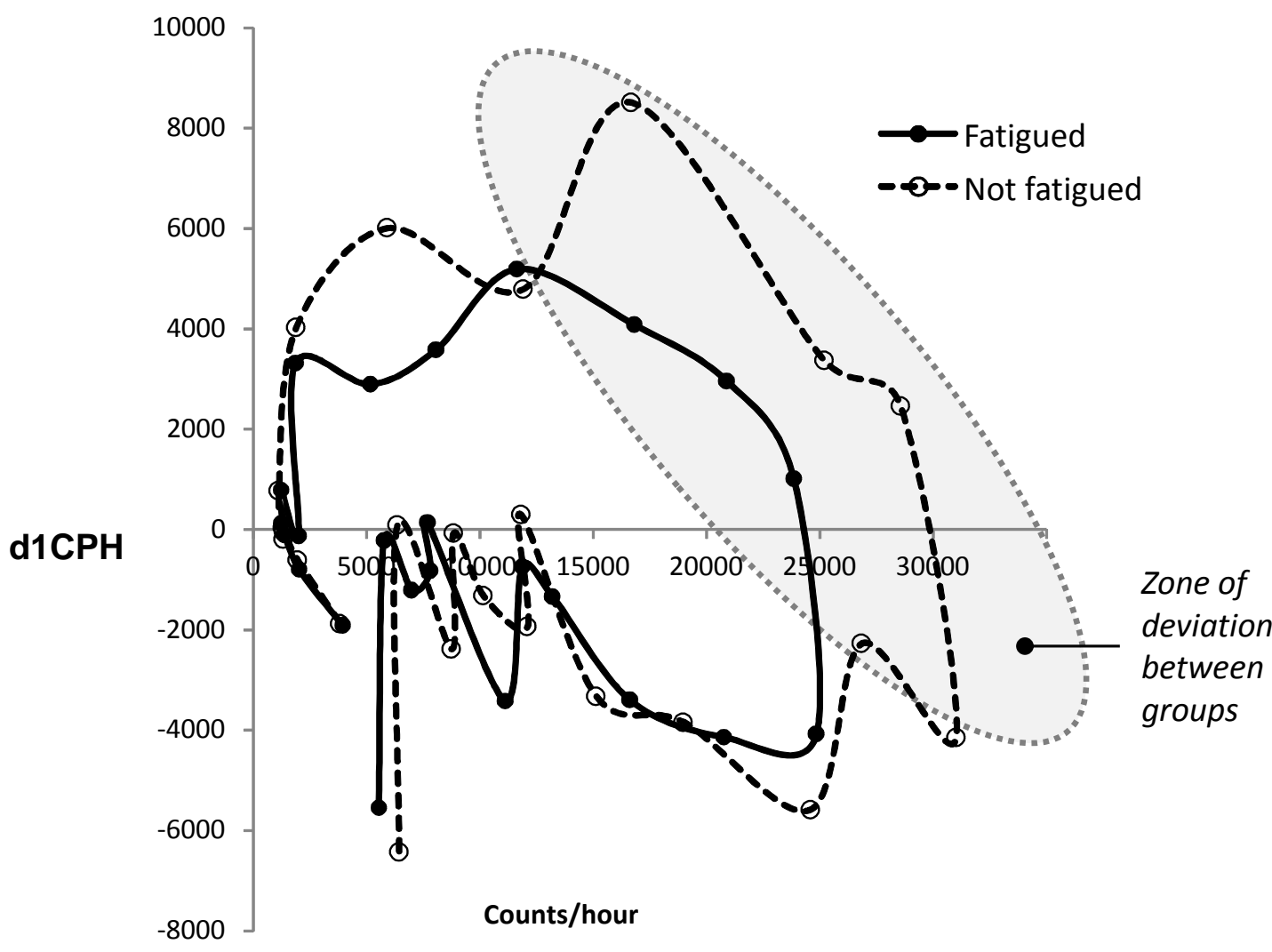

Figure 3. Phase-space plot showing the temporal pattern of energy expending activity. The trajectory represents the dynamics of the hourly change in activity. From the graph it can be deducted that there is a deviation between the groups in the dynamics of energy expending activity and that there are two linear regions (morning and afternoon). 
"Fatigue Alters the Pattern of Physical Activity Behaviour in Older Adults: Observational Analysis of Data from the Generation 100 Study" by Egerton T Helbostad JL, Stensvold D, Chastin S FM

Journal of Aging and Physical Activity

(C) 2016 Human Kinetics, Inc.
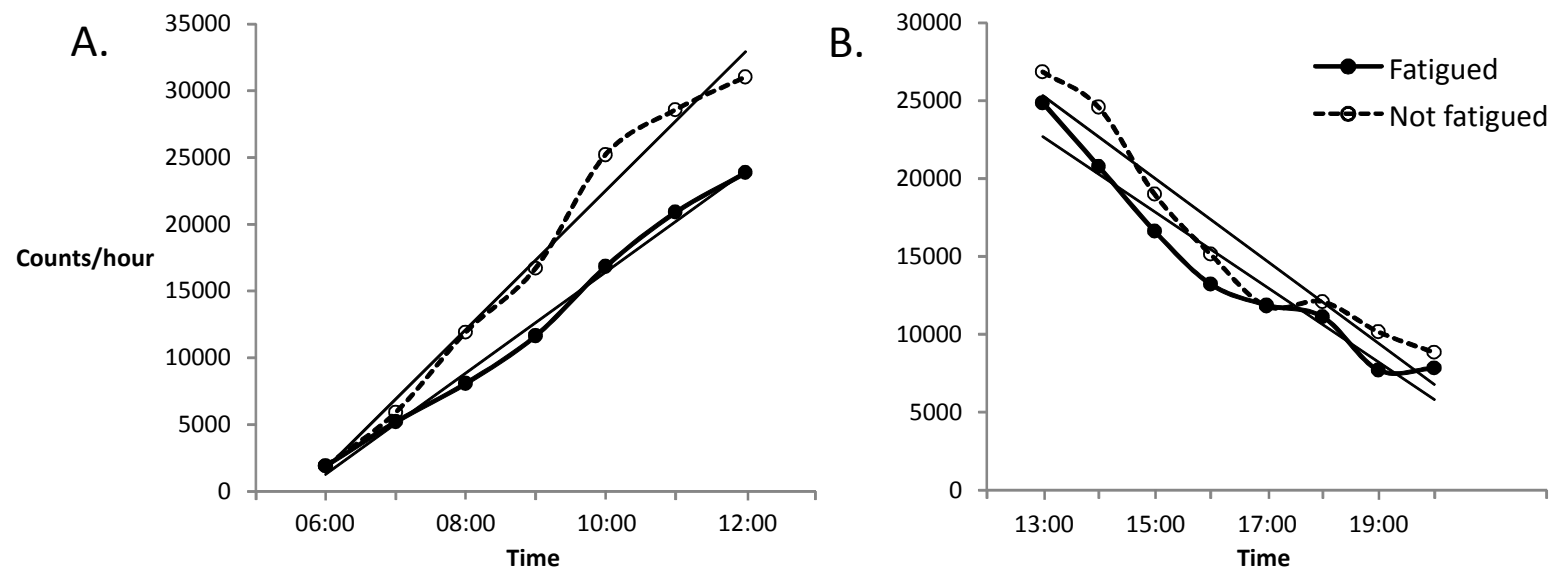

Figure 4. Morning and afternoon/evening counts per hour for fatigued and not fatigued groups with regression lines. 
"Fatigue Alters the Pattern of Physical Activity Behaviour in Older Adults: Observational Analysis of Data from the Generation 100 Study" by Egerton T Helbostad JL, Stensvold D, Chastin S FM

Journal of Aging and Physical Activity

(C) 2016 Human Kinetics, Inc.

Table 1. Fatigue Severity Scale items (7-item English version).

This questionnaire contains seven statements that rate the severity of your fatigue symptoms. Read each statement and circle a number from 1 to 7 , based on how accurately it reflects your condition during the past week and the extent to which you agree or disagree that the statement applies to you.

During the past week, I have found that:

1. I am easily fatigued.

2. Fatigue interferes with my physical functioning.

3. Fatigue causes frequent problems for me.

4. My fatigue prevents sustained physical functioning.

5. Fatigue interferes with carrying out certain duties and responsibilities.

6. Fatigue is among my three most disabling symptoms.

7. Fatigue interferes with my work, family or social life.

Reference: Krupp LB, LaRocca NG, Muir-Nash J, Steinberg AD. The fatigue severity scale. Application to patients with multiple sclerosis and systemic lupus erythematosus. Arch Neurol. 1989;46(10):1121-1123. 
"Fatigue Alters the Pattern of Physical Activity Behaviour in Older Adults: Observational Analysis of Data from the Generation 100 Study" by Egerton T Helbostad JL, Stensvold D, Chastin S FM

Journal of Aging and Physical Activity

(C) 2016 Human Kinetics, Inc.

Table 2. Descriptive data. Group differences analysed with t-test, Mann-Whitney U test or ChiSquare test as appropriate.

\begin{tabular}{|c|c|c|c|}
\hline & Fatigued $(n=86)$ & Not Fatigued $(n=86)$ & $p$-value \\
\hline Age, mean years (SD, range) & $73.9(2.0,71-77)$ & $73.7(2.0,71-77)$ & \\
\hline BMI, mean kg.m $\mathrm{m}^{-2}$ (SD, range) & $26.6(4.1,19.0-42.1)$ & $26.5(3.7,18.7-35.7)$ & \\
\hline Sex, $\mathrm{n}$ female (\%) & $52(61 \%)$ & $52(61 \%)$ & \\
\hline $\begin{array}{l}\text { Average counts per minute, mean CPM } \\
\text { (SD) }\end{array}$ & $180(72)$ & $217(78)$ & 0.002 \\
\hline Mean counts per hour, mean CPH (SD) & $9,726(3,960)$ & $11,780(4170)$ & 0.001 \\
\hline Maximum counts per hour, mean (SD) & $36,297(19,970)$ & $47,544(25,528)$ & 0.002 \\
\hline $\begin{array}{l}\text { Average daily step count, mean steps/day } \\
\text { (SD) }\end{array}$ & $5466(2138)$ & $6604(1958)$ & $<0.001$ \\
\hline $\begin{array}{l}\text { Cardiorespiratory fitness ( } \mathrm{VO}_{2} \text { peak), } \\
\text { mean } \mathrm{ml} / \mathrm{min} / \mathrm{kg} \text { (SD) }\end{array}$ & $25.8(6.4)$ & $28.5(7.0)$ & 0.009 \\
\hline Preferred gait speed, mean m/s (SD) & $1.22(0.18)$ & $1.33(0.17)$ & $<0.001$ \\
\hline Chronic conditions & $2.9(2.2,1-10)$ & $1.8(1.4,1-7)$ & $<0.001$ \\
\hline History of cardiovascular disease, yes (\%) & $19(22 \%)$ & $8(9 \%)$ & 0.021 \\
\hline Sleep & $6.0(1.5,3-9)$ & $5.1(1.4,3-9)$ & $<0.001$ \\
\hline Depression (HADS), mean (SD, range) & $11.4(2.6,7-18)$ & $9.2(2.0,7-17)$ & $<0.001$ \\
\hline $\begin{array}{l}\text { Number of prescription medications, } \\
\text { mean (SD, range) }\end{array}$ & $2.7(2.2,0-10)$ & $2.0(1.6,0-6)$ & 0.057 \\
\hline
\end{tabular}

$\mathrm{BMI}=$ body mass index, $\mathrm{CPM}=$ counts per minute, $\mathrm{CPH}=$ counts per hour, $\mathrm{HADS}=$ Hospital anxiety and depression scale. 